\title{
Successful treatment using a side-viewing duodenoscope for esophagojejunal varices on the jejunal side of the anastomosis site after total gastrectomy
}

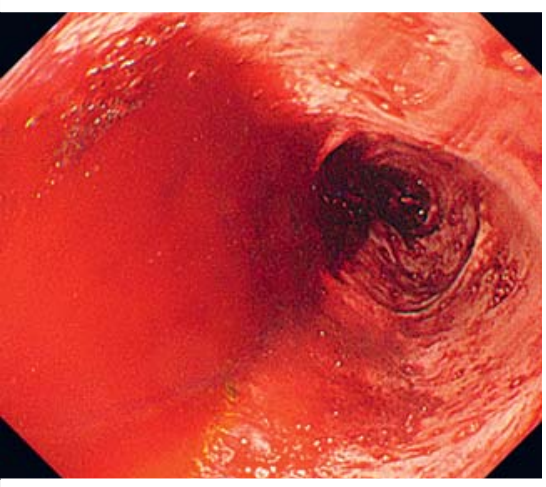

-Fig. 1 Emergency endoscopy revealed massive hemorrhage in the esophagus.

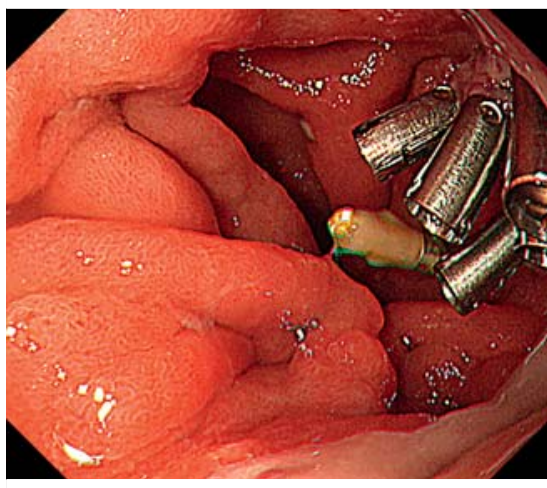

Fig. 4 Esophagogastroduodenoscopy performed 2 days after the procedure revealed hemostasis of the esophagojejunal varices.

Esophagojejunal varices arising after total gastrectomy and esophagojejunostomy are a rare complication of portal hypertension [1-3]. Endoscopic treatments can become challenging due to fibrosis and bleeding on the jejunal side after anastomosis. Few reports have documented the successful treatment of esophagojejunal varices after gastrectomy. We report a case of esophagojejunal variceal hemorrhage treated using a side-viewing duodenoscope.

A 67-year-old man, who underwent a total gastrectomy for gastric cancer 12 years previously, presented to our hospital with massive melena. He had a history

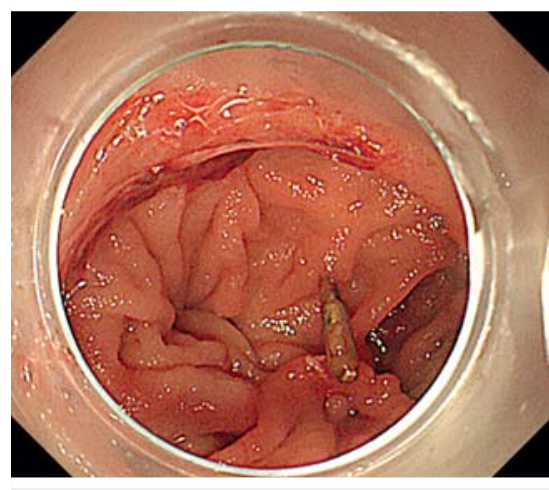

- Fig. 2 The bleeding point could not be observed during esophagogastroduodenoscopy as it was on the inside of the anastomosis.

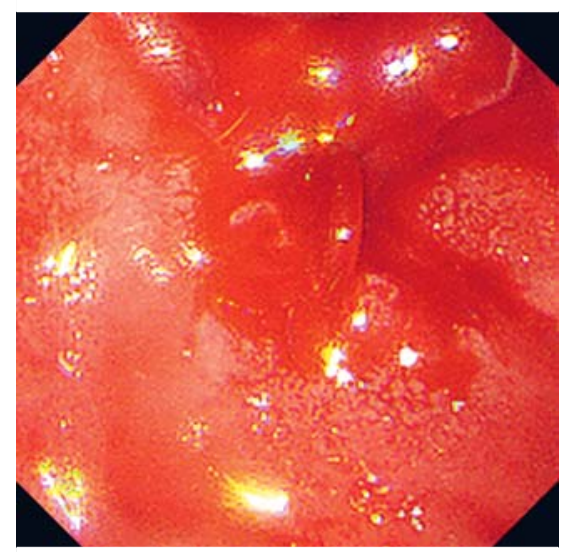

- Fig. 3 The bleeding point could be visualized by a side-viewing duodenoscope.

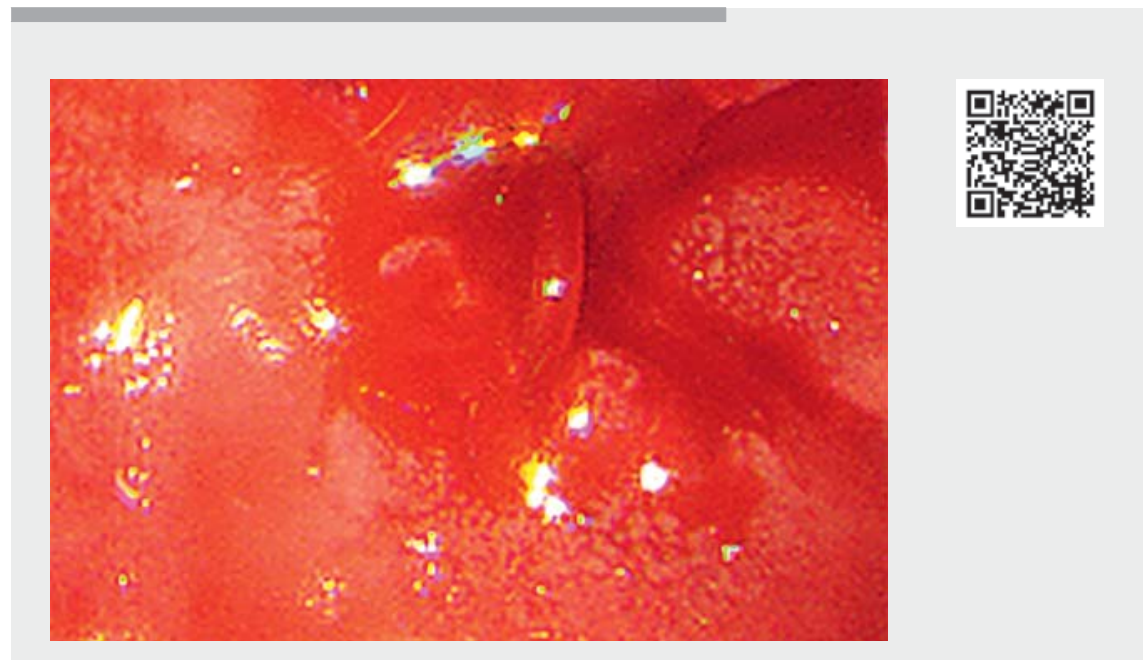

Video 1 Successful treatment using a side-viewing duodenoscope for hemorrhage due to esophagojejunal varices on the jejunal side of the anastomosis site after total gastrectomy.

of alcoholic cirrhosis and esophageal variceal bleeding. Abdominal contrast-enhanced computed tomography showed a dilated vein in the elevated jejunal limb supplying the varices. He was diagnosed with hemorrhage due to esophagojejunal varices. However, the varices were thin, and interventional radiology was difficult. Therefore, endoscopic treatment was attempted.
First, we performed esophagogastroduodenoscopy (EGD) (GIF-H290; Olympus Co., Tokyo, Japan), which revealed massive hemorrhage in the esophagus and jejunum ( Fig.1). However, we could not observe the bleeding point because it was located inside the anastomosis. As cap attachment was ineffective ( Fig. 2), a side-viewing duodenoscope (JF-260V; Olympus Co.) was used, 
and the bleeding point was clearly visualized on the jejunal side of the anastomosis (> Fig.3); however, endoscopic variceal ligation was deemed to be difficult owing to the close proximity to the anastomosis site. We therefore used clips (SureClip; Micro-Tech Co., Ltd., Nanjing, China) to treat the bleeding ( $\triangleright$ Video 1 ). Clips could be applied easily as the bleeding point was clearly observed using the side-viewing duodenoscope.

No adverse events occurred after the endoscopic procedure. EGD 2 days postprocedure confirmed that there was no bleeding ( $>$ Fig.4). The described method had advantages over EGD as the inside of the anastomosis could be visualized with the side-viewing duodenoscope and only a change in endoscope was required.

Endoscopy_UCTN_Code_CCL_1AB_2AC_3AG

\section{Competing interests}

The authors declare that they have no conflict of interest.
The authors

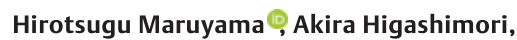
Natsumi Maeda, Masaki Ominami, Shusei Fukunaga, Yasuaki Nagami, Yasuhiro Fujiwara Department of Gastroenterology, Osaka City University Graduate School of Medicine

\section{Corresponding author}

\section{Hirotsugu Maruyama, MD, PhD}

Department of Gastroenterology, Osaka

City University Graduate School of Medicine, 1-4-3, Asahimachi, Abeno-ku, Osaka 5458585, Japan

hiromaruyama99@gmail.com

\section{References}

[1] Chikamori F, Aoyagi H, Takagaki T et al. Injection sclerotherapy for esophageal varices after total gastrectomy: case reports of two patients. Dig Endosc 1992; 4: 274-280

[2] Chikamori F, Shibuya S, Takase Yet al. Percutaneous transhepatic obliteration for esophagojejunal varices after total gastrectomy. Abdom Imaging 1998; 23: 560-562

[3] Ishizuka D, Tsukada K, Sakaguchi T et al. A portal angiographic sign in a patient with esophageal varices following total gastrectomy and esophagojejunostomy. Acta Med Biol 1996; 44: 169-172
Bibliography

Endoscopy 2022; 54: E484-E485

DOI 10.1055/a-1625-5369

ISSN 0013-726X

published online 8.10 .2021

(c) 2021. Thieme. All rights reserved.

Georg Thieme Verlag KG, Rüdigerstraße 14,

70469 Stuttgart, Germany

\section{ENDOSCOPY E-VIDEOS}

https://eref.thieme.de/e-videos

回回 Endoscopy E-Videos is an 整到 自: reporting on interesting cases and new techniques in gastroenterological endoscopy. All papers include a high quality video and all contributions are freely accessible online. Processing charges apply (currently EUR 375), discounts and wavers acc. to HINARI are available.

This section has its own submission website at https://mc.manuscriptcentral.com/e-videos 